BMJ Open

Diabetes

Research

\& Care

\title{
Validity and reliability of anti-diabetic medication adherence scale among patients with diabetes in Baghdad, Iraq: a pilot study
}

\author{
Ehab Mudher Mikhael, ${ }^{\oplus 1,2}$ Saad A Hussain, ${ }^{3}$ Nizar Shawky, ${ }^{4}$ \\ Mohamed Azmi Hassali ${ }^{2}$
}

To cite: Mikhael EM, Hussain SA, Shawky N, et al. Validity and reliability of anti-diabetic medication adherence scale among patients with diabetes in Baghdad, Iraq: a pilot study. BMJ Open Diab Res Care 2019;7:e000658. doi:10.1136/ bmjdrc-2019-000658

\section{- Additional material is published online only. To view please visit the journal online (http://dx.doi.org/10.1136/ bmjdrc-2019-000658).}

Received 25 January 2019 Revised 6 May 2019 Accepted 3 June 2019

\section{Check for updates}

(C) Author(s) (or their employer(s)) 2019. Re-use permitted under CC BY-NC. No commercial re-use. See rights and permissions. Published by BMJ.

${ }^{1}$ Clinical Pharmacy Department, College of Pharmacy, University of Baghdad, Baghdad, Iraq 2Department of Social and Administrative Pharmacy, School of Pharmaceutical Sciences, Universiti Sains Malaysia, Penang, Malaysia ${ }^{3}$ School of Pharmacy, AlRafidain University College, Baghdad, Iraq

${ }^{4}$ National Diabetes Center, Al-Mustansiriyah University, Baghdad, Iraq

\section{Correspondence to} Dr Ehab Mudher Mikhael; ehab_pharma84@yahoo.com

\section{ABSTRACT}

Background Medication non-adherence is a common problem among patients with diabetes. Patient-reported medication adherence scales are the most commonly used method to assess patient medication adherence, but up to today there is no specific tool for assessing medication adherence among patients with diabetes in Arab countries. This study aimed to develop and validate a new tool for assessment of adherence to antidiabetic medications among Iraqi patients with diabetes.

Methods The Iraqi Anti-Diabetic Medication Adherence Scale (IADMAS) consists of eight items. The face and content validity of the IADMAS were established via an expert panel. For convergent validity, the IADMAS was compared with the Medication Adherence Questionnaire (MAQ). For concurrent validity, the IADMAS was compared with glycosylated hemoglobin. A total of 84 patients with types 2 diabetes were recruited from a diabetes center in Baghdad, Iraq. Test-retest reliability was measured by readministering the IADMAS to the same patients 4 weeks later.

Results Only 80 patients completed the study (response rate: $95 \%$ ). Reliability analysis of the IADMAS showed a Cronbach's alpha value of 0.712 , whereas that of the MAQ was 0.649. All items in the IADMAS showed no significant difference in the test-retest analysis, indicating that the IADMAS has stable reliability. There was no difference in the psychometric properties of the IADMAS and the MAQ. The sensitivity and specificity of the IADMAS were higher than that of the MAQ $(100 \%$ vs $87.5 \%$ and $33.9 \%$ vs $29.7 \%$, respectively).

Conclusion The IADMAS developed in this study is a reliable and valid instrument for assessing antidiabetic medication adherence among Iraqi patients.

\section{INTRODUCTION}

Diabetes mellitus (DM) is a chronic metabolic disorder that has shown a dramatically increased incidence in recent decades. ${ }^{1} \mathrm{DM}$ can cause many acute and chronic complications that may be associated with significant morbidity and mortality. ${ }^{23}$ Glycemic control can effectively reduce diabetic complications and enhance the patient's quality of life. $^{2}$ Glycemic control can be achieved

\section{Significance of this study}

What is already known about this subject?

- There are many validated tools to assess medication adherence.

What are the new findings?

- The newly developed tool is the first tool developed in Arabic and specific for Iraqi patients with diabetes.

How might these results change the focus of research or clinical practice?

- This tool can be used to assess and indirectly to improve medication adherence among Iraqi patients with diabetes.

- Additionally, the validity and reliability of this tool can be assessed in all Arabic countries.

mainly through the utilization of pharmacologic treatment. ${ }^{5}$ Meanwhile, adherence to the pharmacologic treatment is necessary to ensure maximum treatment-related benefits. ${ }^{67}$ Unfortunately, lack of adherence is a common problem among patients with type 2 DM. $^{8}$ It was found that non-adherence to antidiabetic medications can be associated with poor glycemic control and with increased costs through increasing use of healthcare resources. ${ }^{9} 10$ Patient-reported tools (scales) are commonly used to assess adherence among patients with DM because they are reliable and practical. ${ }^{11-13}$ Most of the currently valid and commonly used tools to assess antidiabetic medication adherence, such as the Medication Adherence Questionnaire (MAQ), the Morisky Medication Adherence Scale - eight items (MMAS-8), the Medication Adherence Rating Scale, and the Adherence to Refills and Medication Scale, are lacking specificity since they were not originally designed for assessing adherence among patients with diabetes. ${ }^{11} 14$ Additionally, all of the above scales were structured 
and developed to test medication adherence for patients in developed countries. On the other hand, few scales were designed to assess medication adherence among patients with diabetes in developing countries, such as the Malaysian Medication Adherence Scale (MALMAS) ${ }^{15}$ It is well known that personal and cultural beliefs can affect patient medication adherence ${ }^{16}$; this means that all of these scales may not be suitable for assessing medication adherence among Iraqi patients even after a valid translation process because the culture and patients' beliefs at which these scales were developed are somewhat different from that in Iraq. Therefore, this study aimed to develop a new tool for the assessment of adherence to antidiabetic medications among Iraqi patients with type 2 DM.

\section{PATIENTS AND METHODS}

Development of the Iraqi Anti-Diabetic Medication Adherence Scale

Literature review of self-reported medication adherence scales among patients with diabetes was done through the use of the following sets of keywords. The first set of keywords includes "evaluation of adherence and diabetes mellitus", while the second set includes "medication adherence scale and diabetes mellitus". Although many studies were detected, only those with freely available questionnaires were selected, such as the MAQ ${ }^{17}$ Measurement of Adherence to the Treatment, ${ }^{18}$ and Medication Compliance Questionnaire. ${ }^{19}$

Additional review of the literature was carried out by searching Google Scholar and PubMed to look for articles about the perception of Iraqi patients with diabetes toward diabetes treatment using the following keywords: perception, diabetes treatment and Iraq; besides, the results of a recent qualitative study that was done to assess self-management practices and medication-taking behavior among Iraqi patients with type $2 \mathrm{DM}$ were also taken into account. ${ }^{20-22}$ The main reasons for medication non-adherence among Iraqi patients were carelessness, forgetfulness, high medication cost, disappearance of the disease symptoms, medication-related side effects, reduced appetite during sick days and going outside home.

Then all of the selected scales were carefully assessed to find out questions that can fit to evaluate adherence to antidiabetic medications among Iraqi patients. Six items were relevant to the Iraqi patients with DM and thus were adapted from the aforementioned scales. Additionally, two new items were added to the Iraqi Anti-Diabetic Medication Adherence Scale (IADMAS) to increase its sensitivity and specificity in predicting non-adherence among Iraqi patients with diabetes; the first added item was intended to assess the effect of medication cost on medication adherence, while the second one was intended to assess patients' adherence to the prescribed medication dose during sick days while the appetite is mostly reduced. ${ }^{23}$
In total, the IADMAS (online supplementary 1) consists of eight items; three items are used to directly assess medication-taking behavior by giving five responses: (1) always (daily), (2) often, (3) sometimes, (4) rarely and (5) never. The remaining five items are used to measure the determinant of non-adherence by giving a dichotomous response of "Yes" or "No".

The first item aims to identify the extent of unintentional missing of medication doses; all other questions were directed to identify the extent of intentional medication non-adherence. Two items (1 and 3) were used to identify the extent of non-adherence to the time of medication taking. Four items (2, 6, 7 and 8) were formulated to identify the extent of intentional non-adherence with the prescribed medication dose. Only one item (5) aims to identify the extent of intentional non-adherence through discontinuation of taking DM medication.

Scoring of all items ranged from 0 to 1 , 0 for non-adherent answer and 1 for total adherence. All items, except item 4 , are inversely calculated. The first three items use a 5-point Likert scale that can take one of five values: 1 , $0.75,0.5,0.25$ or 0 .

The total score of the IADMAS ranged from 0 to 8 . Medication adherence in the IADMAS was categorized into three levels of adherence: high adherence (total score $=8)$, medium adherence ( 6 to $<8)$ and low adherence $(<6){ }^{24}$

\section{VALIDATION OF THE IADMAS Translation}

Both the MAQ and the six selected questions from the previously validated scales were translated to Arabic using a forward and backward translation method. Some of the translated questions were modified to ensure maximum understanding by the Iraqi patients. On the other hand, the Arabic questions of the IADMAS (final version) were also translated to English using a forward and backward translation method.

\section{Face and content validity}

A research team consisting of two diabetes educators, three clinical pharmacists, one diabetologist and one psychiatrist established the face and content validity of the Arabic and the English versions of the IADMAS; meanwhile, further validations were done only for the Arabic version. A pilot study was conducted on seven Iraqi patients with $\mathrm{DM}$; they were asked to read the Arabic version of the IADMAS and then reply to the main author with their feedback on the clarity of each question in the IADMAS. All patients agreed on the clarity of the IADMAS questions.

\section{Convergent validity}

The IADMAS has not been validated and hence should be compared with an already validated questionnaire to assess its convergent validity. To date, there is no validated or gold-standard patient-reported measure of medication adherence in Iraq to be used for comparison. The MAQ 
was chosen as a comparator because it was already validated to assess adherence among patients with diabetes, in addition to its ease of use. ${ }^{172526}$

\section{Concurrent validity}

For assessing concurrent validity, the glycosylated hemoglobin (HbA1c) value was chosen as a comparator to the IADMAS because it better correlates with the patient's glycemic control during the previous 2-3 months; besides, it need not be measured in a fasting state. ${ }^{27} 28$ HbAlc was measured using a point of care apparatus (i-chroma, UAE).

\section{Study design}

A cross-sectional study was conducted from the end of October 2017 to March 2018 in the National Diabetes Center, Baghdad, Iraq.

\section{Sample size}

There is uncertainty about the required sample size in pilot studies for validation of the new questionnaires. According to the rule of thumb, 5-10 participants per item can be considered sufficient, but as the sample size increased the accuracy of results can be also increased. ${ }^{29} 30$ The sample size for this study was set at 80 to achieve 10 participants per item (IADMAS has eight items), with an assumption of $5 \%$ for no response. Therefore, the target sample size was 84 patients.

\section{Patient selection}

A convenient sample of 84 patients were recruited by the main researcher in the waiting area of the National Diabetes Center, Baghdad, Iraq.

Only Arab patients older than 18 years, having type $2 \mathrm{DM}$ and maintained on antidiabetic medications for at least 3 months were included in this study. However, patients who had renal impairment, cognitive impairment and depression and pregnant women were excluded.

Prior to recruitment, all patients were asked (by the main researcher) two questions specific for initial diagnosis of depression, to exclude patients with suspected but undiagnosed depression ${ }^{31}$ and refer those with abnormal answers to the psychiatrist.

All patients were interviewed by the main researcher to explain the purpose and the study protocol; only those who provided their informed consent were requested to complete a set of self-administered questionnaires that include the IADMAS and the MAQ. The questionnaires were presented to patients with low educational level (13 patients) and to patients with visual impairment (3 patients) via face-to-face interview. The interviews were conducted by the main researcher.

The participants need approximately $5-10 \mathrm{~min}$ to complete the two questionnaires.

Only 24 patients who were maintained on the same treatment (the same medication and same dose) were asked to return back after 2 weeks to fill in the IADMAS.

\section{IADMAS diagnostic accuracy}

Patients with $\mathrm{HbAlc}$ values of less than 7 were considered to have good glycemic control. ${ }^{28}$ The association between medication adherence and glycemic control was used to measure true positive (TP) results (patients who are non-adherent to their treatment and have poor glycemic control), false positive (FP) results (patients with poor glycemic control despite being adherent to their treatment), true negative (TN) results (patients with good glycemic control and good medication adherence), and false negative $(\mathrm{FN})$ results (patients with good glycemic control despite being non-adherent to their treatment).

The sensitivity of the IADMAS measures its ability to correctly predict poor glycemic control in non-adherent patients, while the specificity of the IADMAS measures its ability to correctly predict good glycemic control in adherent patients. Positive predictive value (also called precision rate) is the proportion of positive test results that are TPs. This value measures how likely non-adherent patients have poor glycemic control; meanwhile, the negative predictive value is the proportion of patients with a negative test result. ${ }^{32}$ This value measures how likely adherent patients have good glycemic control.

Specificity and sensitivity, as well as positive and negative predictive values, for the IADMAS were measured using the following equations:

\begin{tabular}{|c|c|}
\hline Parameter & Value \\
\hline Age (years), mean $\pm S D$ (range) & $55.28 \pm 9.02(33-76)$ \\
\hline \multicolumn{2}{|l|}{ Gender } \\
\hline Male & 48 \\
\hline Female & 32 \\
\hline \multicolumn{2}{|l|}{ Educational level } \\
\hline None or primary & 15 \\
\hline Secondary & 17 \\
\hline Diploma or college & 44 \\
\hline Postgraduate & 4 \\
\hline $\begin{array}{l}\text { Duration of diabetes mellitus, } \\
\text { mean } \pm S D \text { (range) }\end{array}$ & $\begin{array}{l}9.33 \pm 7.02 \text { ( } 4 \text { months }-31 \\
\text { years) }\end{array}$ \\
\hline $\begin{array}{l}\text { Number of prescribed } \\
\text { medications, mean } \pm S D \text { (range) }\end{array}$ & $1.62 \pm 0.65(1-5)$ \\
\hline \multicolumn{2}{|l|}{ Type of medication } \\
\hline Oral & 43 \\
\hline Injectable & 21 \\
\hline Combination & 16 \\
\hline $\begin{array}{l}\text { Duration on treatment in years, } \\
\text { mean } \pm S D \text { (range) }\end{array}$ & $1.69 \pm 2.31(0.2-12)$ \\
\hline $\begin{array}{l}\text { Glycosylated hemoglobin, } \\
\text { mean } \pm S D \text { (range) }\end{array}$ & $9.04 \pm 2.45(5.0-14.5)$ \\
\hline $\begin{array}{l}\text { Frequency of drug usage, } \\
\text { mean } \pm S D \text { (range) }\end{array}$ & $2.61 \pm 0.93(1-5)$ \\
\hline
\end{tabular}

$\mathrm{SD}$, Standard deviation. 
Table 2 Reliability of IADMAS and MAQ

\begin{tabular}{llllll}
\hline & IADMAS & & MAQ & \\
\cline { 2 - 3 } Parameter & $\begin{array}{l}\text { Corrected item-total } \\
\text { correlation }\end{array}$ & $\begin{array}{l}\text { Cronbach's alpha if } \\
\text { item deleted }\end{array}$ & & $\begin{array}{l}\text { Corrected item-total } \\
\text { correlation }\end{array}$ & $\begin{array}{l}\text { Cronbach's alpha if } \\
\text { item deleted }\end{array}$ \\
\hline Q1 & 0.396 & 0.689 & 0.345 & 0.644 \\
Q2 & 0.551 & 0.651 & 0.246 & 0.706 \\
\hline Q3 & 0.148 & 0.721 & 0.605 & 0.455 \\
\hline Q5 & 0.378 & 0.693 & 0.579 & 0.486 \\
\hline Q6 & 0.636 & 0.629 & & \\
\hline Q7 & 0.547 & 0.647 & & \\
Q8 & 0.375 & 0.690 & & \\
\hline $\begin{array}{l}\text { Overall Cronbach's } \\
\text { alpha score }\end{array}$ & 0.201 & 0.712 & & 0.6424 & \\
\hline
\end{tabular}

IADMAS, Iraqi Anti-Diabetic Medication Adherence Scale; MALMAS, Malaysian Medication Adherence Scale; MAQ, Medication Adherence Questionnaire.

Positive predictive value $=\mathrm{TP} /(\mathrm{TP}+\mathrm{FP}) \times 100 \%$

Negative predictive value $=\mathrm{TN} /(\mathrm{TN}+\mathrm{FN}) \times 100 \%$

Sensitivity $=\mathrm{TP} /(\mathrm{TP}+\mathrm{FN}) \times 100 \%$

Specificity $=\mathrm{TN} /(\mathrm{TN}+\mathrm{FP}) \times 100 \%$

\section{Statistical analysis}

Data input and analysis were done using the Statistical Package for the Social Sciences (SPSS) V.17. Categorical variables were presented as percentage and frequencies, while mean and SD were used to present continuous variables. $\chi^{2}$ test was used to measure the difference among categorical variables. The Kolmogorov-Smirnov test was used to test the normal distribution of continuous variables. Mann-Whitney U test was used to test the mean difference between continuous variables. Spearman's correlation test was used to determine the correlation between continuous variables. Cronbach's alpha values were used to determine the internal consistency of the IADMAS and the MAQ. A Cronbach's alpha value of more than 0.7 was considered optimum. A value of any corrected item-total correlation which is higher than

\begin{tabular}{lcl}
\hline Table 3 & IADMAS test-retest reliability & \\
\hline Parameter & $\begin{array}{l}\text { Z score for test-retest } \\
\text { mean difference }\end{array}$ & P value \\
\hline Q1 & -1.633 & 0.102 \\
Q2 & -1.131 & 0.258 \\
Q3 & 0 & 1 \\
Q4 & 0 & 1 \\
Q5 & -0.577 & 0.564 \\
Q6 & -1.414 & 0.157 \\
Q7 & 0 & 1 \\
Q8 & -1 & 0.317 \\
Total score correlation & 0.806 & 0.016 \\
\hline
\end{tabular}

IADMAS, Iraqi Anti-Diabetic Medication Adherence Scale.
0.2 is considered acceptable. ${ }^{33}$ Test-retest reliability was assessed using Wilcoxon signed-rank test to measure score difference for each item, while Spearman's correlation coefficient was used to test the correlation of the IADMAS total score before and after retesting. $\mathrm{P}$ values $<0.05$ were considered statistically significant.

\section{RESULTS}

A total of 84 participants were recruited in this study; however, only 80 patients completed this study (response rate: $95.2 \%$ ). Patients' demographic and clinical data are presented in table 1 .

\section{Psychometric properties of the IADMAS \\ Reliability analysis}

The internal consistency of the IADMAS and the MAQ was measured using Cronbach's alpha. The Cronbach's alpha values for the IADMAS and the MAQ were 0.712 and 0.649 , respectively. The Cronbach's alpha of the IADMAS will be increased to 0.724 if item 8 was excluded, while for the MAQ this value will be increased to 0.706 if item 2 was deleted. The item-total correlations were less than 0.2 for one item (item 3) in the IADMAS (table 2).

In table 3, the Spearman's $r$ for the total score of testretest reliability was $0.806(\mathrm{p}=0.016)$. When the individual items in the the IADMAS were analyzed, no any item was significantly different at test-retest $(\mathrm{p}>0.05)$.

\begin{tabular}{|c|c|c|c|}
\hline Parameter & Parameter & Pearson coefficient & $P$ value \\
\hline IADMAS & HbA1c & -0.423 & 0.000 \\
\hline IADMAS & MAQ & 0.682 & 0.000 \\
\hline
\end{tabular}

HbA1c, glycosylated hemoglobin; IADMAS, Iraqi Anti-Diabetic Medication Adherence Scale; MAQ, Medication Adherence Questionnaire. 
Table 5 Correlation of IADMAS subscales with $\mathrm{HbA1c}$, MAQ and IADMAS scores

\begin{tabular}{llll}
\hline & \multicolumn{3}{l}{ Correlation coefficient } \\
\cline { 2 - 4 } Parameter (questions) & HbA1c & IADMAS & MAQ \\
\hline $\begin{array}{l}\text { Intentional non- } \\
\text { adherence (Q2-Q8) }\end{array}$ & $-0.370^{\star *}$ & $0.962^{\star *}$ & $0.702^{\star *}$ \\
$\begin{array}{l}\text { Unintentional non- } \\
\text { adherence subscale (Q1) }\end{array}$ & $-0.382^{\star *}$ & $0.521^{\star *}$ & $0.290^{\star *}$ \\
$\begin{array}{l}\text { Non-adherence to time } \\
\text { of medication taking (Q1 } \\
\text { and Q3) }\end{array}$ & $-0.390^{\star *}$ & $0.571^{\star *}$ & $0.277^{\star}$ \\
$\begin{array}{l}\text { Non-adherence to } \\
\text { medication dose } \\
\text { (Q2, Q6, Q7 and Q8) }\end{array}$ & $-0.368^{\star *}$ & $0.880^{\star *}$ & $0.769^{\star *}$ \\
$\begin{array}{l}\text { Intentional stop taking of } \\
\text { medications (Q5) }\end{array}$ & $-0.249^{*}$ & $0.586^{\star *}$ & $0.481^{\star *}$ \\
$\begin{array}{l}\text { Newly added questions } \\
\text { (8 }\end{array}$ & $-0.445^{\star *}$ & $0.721^{\star *}$ & $0.968^{\star *}$ \\
\hline
\end{tabular}

${ }^{*} \mathrm{P}<0.05,{ }^{* *} \mathrm{p}<0.01$.

HbA1c, glycosylated hemoglobin; IADMAS, Iraqi Anti-Diabetic

Medication Adherence Scale; MAQ, Medication Adherence

Questionnaire.

\section{Convergent and concurrent validity}

In table 4 , there was a highly significant correlation between the IADMAS and the MAQ (Spearman's $\mathrm{r}=0.682, \mathrm{p}=0.000$ ). Additionally, the scores of all IADMAS subscales were positively correlated with overall MAQ and IADMAS scores (table 5). Furthermore, there was a non-significant difference between the IADMAS and the $\mathrm{MAQ}$ in the number of patients at different adherence levels (table 6).

There was a significant inverse correlation between HbA1c values and the total scores of the IADMAS (Spearman's $\mathrm{r}=-0.423, \mathrm{p}=0.000$ ) (table 4). Additionally, all IADMAS subscales showed a significantly weak negative correlation with the HbAlc values, except for the newly added items which have a moderate inverse correlation with HbA1c (table 5). Furthermore, the mean values of HbAlc were significantly different at different levels of medication adherence (table 7).

\begin{tabular}{|c|c|c|c|}
\hline Parameter & IADMAS & MAQ & $P$ value \\
\hline Low adherence & $18(22.5 \%)$ & $16(20 \%)$ & 0.532 \\
\hline Moderate adherence & $33(41.25 \%)$ & $40(50 \%)$ & \\
\hline High adherence & $29(36.25 \%)$ & $24(30 \%)$ & \\
\hline $\begin{array}{l}\text { High (absolute) } \\
\text { adherence }\end{array}$ & $29(36.25 \%)$ & $24(30 \%)$ & 0.401 \\
\hline Non-adherence & $51(63.75 \%)$ & $56(70 \%)$ & \\
\hline $\begin{array}{l}\text { High and moderate } \\
\text { adherence }\end{array}$ & $62(77.5 \%)$ & $64(80 \%)$ & 0.699 \\
\hline Low adherence & $18(22.5 \%)$ & $16(20 \%)$ & \\
\hline
\end{tabular}

IADMAS, Iraqi Anti-Diabetic Medication Adherence Scale; MAQ, Medication Adherence Questionnaire.
Table 7 Association of $\mathrm{HbA} 1 \mathrm{c}$ with level of medication adherence

\begin{tabular}{llll}
\hline & $\begin{array}{l}\text { HbA1c level } \\
\text { for adherent } \\
\text { patients }\end{array}$ & $\begin{array}{l}\text { HbA1c for } \\
\text { non-adherent } \\
\text { patients }\end{array}$ & P value \\
\hline $\begin{array}{l}\text { All patients } \\
\text { (moderate and high } \\
\text { adherence) }\end{array}$ & $8.42 \pm 2.12$ & $11.16 \pm 2.35$ & 0.000 \\
$\begin{array}{l}\text { Patients with } \\
\text { moderate }\end{array}$ & $8.82 \pm 2.22$ & $11.16 \pm 2.35$ & 0.004 \\
$\begin{array}{l}\text { adherence } \\
\text { Patients with high } \\
\text { adherence }\end{array}$ & $7.98 \pm 1.98$ & $11.16 \pm 2.35$ & 0.000 \\
\hline
\end{tabular}

HbA1c, glycosylated hemoglobin.

\section{IADMAS diagnostic accuracy}

The association between medication adherence and glycemic control, including TP, TN, FP and $\mathrm{FN}$ values for the IADMAS and the MAQ is shown in table 8.

The sensitivity and specificity of the IADMAS were $100 \%$ and $33.9 \%$, respectively. The positive and negative predictive values were calculated as $30.5 \%$ and $100 \%$, respectively, as shown in table 9 .

\section{DISCUSSION}

This study showed that the IADMAS has optimum internal consistency, stable reliability, and good concurrent validity, sensitivity and specificity.

The psychometric properties of the IADMAS were not significantly different from that of the validated MAQ. Both scales produced Cronbach's alpha coefficients greater than 0.6. Meanwhile, only the IADMAS produced Cronbach's alpha score greater than 0.7 . This result was in tune with a previously reported one, where a low Cronbach's alpha (0.55) was achieved for the MAQ among American patients with diabetes. ${ }^{34}$ Moreover, most references considered a Cronbach's alpha value greater than 0.6 as acceptable and a value greater than 0.7 as optimum. $^{35}$

Table 8 TP, TN, FP and FN values for IADMAS and MAQ

\begin{tabular}{|c|c|c|}
\hline Parameter & $\begin{array}{l}\text { Low adherence, } \\
\text { n (\%) }\end{array}$ & $\begin{array}{l}\text { Moderate and high } \\
\text { adherence, } \mathrm{n}(\%)\end{array}$ \\
\hline \multicolumn{3}{|l|}{ IADMAS } \\
\hline $\begin{array}{l}\text { Poor glycemic control, } \\
\text { HbA1c } \geq 7 \%\end{array}$ & 18 (100) (TP) & $41(66.1)(\mathrm{FP})$ \\
\hline $\begin{array}{l}\text { Good glycemic control, } \\
\mathrm{HbA} 1 \mathrm{c}<7 \%\end{array}$ & $0(0)(\mathrm{FN})$ & 21 (33.9) (TN) \\
\hline \multicolumn{3}{|l|}{$M A Q$} \\
\hline $\begin{array}{l}\text { Poor glycemic control, } \\
\text { HbA1c } \geq 7 \%\end{array}$ & $14(87.5)(T P)$ & 45 (70.3) (FP) \\
\hline $\begin{array}{l}\text { Good glycemic control, } \\
\mathrm{HbA} 1 \mathrm{c}<7 \%\end{array}$ & 2 (12.5) (FN) & 19 (29.7) (TN) \\
\hline
\end{tabular}

FN, false negative; FP, false positive;IADMAS, Iraqi Anti-Diabetic Medication Adherence Scale; MAQ, Medication Adherence Questionnaire; TN, true negative; TP, true positive. 
Table 9 Sensitivity and specificity for IADMAS compared with MAQ

\begin{tabular}{lll}
\hline Parameter & IADMAS (\%) & MAQ (\%) \\
\hline Sensitivity & 100 & 87.5 \\
Specificity & 33.9 & 29.7 \\
Positive predictive value & 30.5 & 23.7 \\
Negative predictive value & 100 & 90.5 \\
\hline
\end{tabular}

IADMAS, Iraqi Anti-Diabetic Medication Adherence Scale; MAQ, Medication Adherence Questionnaire.

The Cronbach's alpha coefficient of the IADMAS was increased slightly if item 8 was excluded from the scale; however, this item was retained in the IADMAS since it was considered an essential variable; besides, the improvement in Cronbach's alpha by excluding this item is marginal and non-significant.

Seven out of eight items showed good corrected itemtotal correlations; in this regard, other validated scales such as the MALMAS and MMAS-8 had some items with low corrected item-total correlations. ${ }^{15}$

The difference at test-retest was statistically non-significant for all IADMAS items. In addition, a good correlation between the test-retest IADMAS total score was obtained. These findings indicate a stable reliability for the IADMAS.

Both the IADMAS and the MAQ showed good correlation. Additionally, the prevalence of medication non-adherence obtained using the IADMAS was not significantly different from that of the MAQ, confirming the convergent validity of the IADMAS.

This study showed a weak but significant inverse correlation between HbAlc values and the total IADMAS scores of the patients; meanwhile, all subscales of IADMAS had a significant inverse correlation with HbAlc. Furthermore, non-adherent patients had significantly higher mean HbAlc levels than those who were adherent. This finding confirmed the concurrent validity of the IADMAS, and it was in tune with other studies that showed a positive correlation between medication adherence and glycemic control. ${ }^{36} 37$

This study showed that the IADMAS had excellent sensitivity but with low specificity, and this problem was nearly common with all self-reporting methods for patient assessment. ${ }^{38}$ The specificity of the IADMAS was slightly higher than that of the MALMAS ${ }^{15}$ but less than the specificity of the MAQ ${ }^{17}$ and the MMAS- $8 .{ }^{39}$ This may be due to the bias in social desirability which may result from face-to-face interview method of administering the questionnaire to many patients ${ }^{40}$; besides, social desirability was very different among cultures and appears to be higher in developing countries such as Iraq. ${ }^{41}$ This explanation was supported by the reported low specificity values of the MAQ (29.7\%) obtained in this study as compared with that obtained $(44 \%-72 \%)$ in studies performed in developed countries. ${ }^{42}$ Additionally, the low specificity of the IADMAS may be attributed to the small sample size. ${ }^{434}$

The present study also showed that the IADMAS had greater sensitivity and specificity than the MAQ $(100 \%$ vs $87.5 \%$ and $33.9 \%$ vs $29.7 \%$, respectively), and this finding may confirm that the IADMAS could be more specific for Iraqi patients with DM since the MAQ was a general tool for assessing adherence. ${ }^{12}$

One of the major limitations of this study was the small sample size recruited from only one diabetes center. In addition, the IADMAS was validated in Arabic language, and hence only Arabic Iraqi patients could be included in the study. Therefore, it is recommended to do further studies to translate and validate the IADMAS in different languages that are common among Iraqis, such as Assyrian, Kurdish, and Turkmen. Furthermore, the IADMAS was only validated for patients with type 2 DM, so further studies are needed to confirm its validity among patients with other types of diabetes.

\section{CONCLUSION}

The study demonstrates that the IADMAS has internal consistency and stable reliability. The psychometric properties of the IADMAS are at least similar or slightly better than that of the validated MAQ. Therefore, the IADMAS is a reliable and valid instrument and can be used for assessing antidiabetic medication adherence among Iraqi patients with type $2 \mathrm{DM}$.

Contributors EMM was involved in presenting the research idea, literature review, developing the Iraqi Anti-Diabetic Medication Adherence Scale, data collection, statistical analysis and writing the manuscript. SAH was responsible for revising the research and the Iraqi Anti-Diabetic Medication Adherence Scale. NS was responsible for revising the Iraqi Anti-Diabetic Medication Adherence Scale and data collection. MAH was responsible for revising the research.

Funding The authors have not declared a specific grant for this research from any funding agency in the public, commercial or not-for-profit sectors.

Competing interests None declared.

Patient consent for publication Not required.

Ethics approval Ethical approval for this study was obtained from the ethical committee at the National Diabetes Center.

Provenance and peer review Not commissioned; internally peer reviewed.

Data availability statement All data were presented in this article.

Open access This is an open access article distributed in accordance with the Creative Commons Attribution Non Commercial (CC BY-NC 4.0) license, which permits others to distribute, remix, adapt, build upon this work non-commercially, and license their derivative works on different terms, provided the original work is properly cited, appropriate credit is given, any changes made indicated, and the use is non-commercial. See: http://creativecommons.org/licenses/by-nc/4.0/.

\section{REFERENCES}

1. Ogurtsova K, da Rocha Fernandes JD, Huang Y, et al. IDF diabetes atlas: global estimates for the prevalence of diabetes for 2015 and 2040. Diabetes Res Clin Pract 2017;128:40-50.

2. Stolar M. Glycemic control and complications in type 2 diabetes mellitus. Am J Med 2010;123:S3-S11.

3. Bertoni AG, Krop JS, Anderson GF, et al. Diabetes-related morbidity and mortality in a national sample of U.S. elders. Diabetes Care 2002;25:471-5

4. Jacobson AM. Impact of improved glycemic control on quality of life in patients with diabetes. Endocr Pract 2004;10:502-8. 
5. Nathan DM, Buse JB, Davidson MB, et al. Medical management of hyperglycemia in type 2 diabetes: a consensus algorithm for the initiation and adjustment of therapy. Diabetes Care 2009;32:193-203.

6. Chaudhury A, Duvoor C, Reddy Dendi VS, et al. Clinical review of antidiabetic drugs: implications for type 2 diabetes mellitus management. Front Endocrinol 2017;8(Suppl 1).

7. Kamuhabwa A, Charles E. Predictors of poor glycemic control in type 2 diabetic patients attending public hospitals in Dar es Salaam. Drug Healthc Patient Saf 2014;6:155-65.

8. Polonsky WH, Henry RR. Poor medication adherence in type 2 diabetes: recognizing the scope of the problem and its key contributors. Patient Prefer Adherence 2016;10:1299-307.

9. Egede LE, Gebregziabher M, Echols C, et al. Longitudinal effects of medication nonadherence on glycemic control. Ann Pharmacother 2014;48:562-70.

10. Egede LE, Gebregziabher M, Dismuke CE, et al. Medication nonadherence in diabetes: longitudinal effects on costs and potential cost savings from improvement. Diabetes Care 2012;35:2533-9.

11. Capoccia K, Odegard PS, Letassy N. Medication adherence with diabetes medication: a systematic review of the literature. Diabetes Educ 2016:42:34-71.

12. Lam WY, Fresco P. Medication adherence measures: an overview. Biomed Res Int 2015;2015(5, supplement):1-12.

13. Stirratt MJ, Dunbar-Jacob J, Crane HM, et al. Self-report measures of medication adherence behavior: recommendations on optimal use. Trans/ Behav Med 2015;5:470-82.

14. Nguyen T-M-U, Caze AL, Cottrell N. What are validated self-report adherence scales really measuring?: a systematic review. $\mathrm{Br} J$ Clin Pharmacol 2014:77:427-45

15. Chung WW, Chua SS, Lai PSM, et al. The Malaysian medication Adherence Scale (MALMAS): concurrent validity using a clinical measure among people with type 2 diabetes in Malaysia. PLoS One 2015;10:e0124275.

16. Chia LR, Schlenk EA, Dunbar-Jacob J. Effect of personal and cultural beliefs on medication adherence in the elderly. Drugs Aging 2006;23:191-202.

17. Morisky DE, Green LW, Levine DM. Concurrent and predictive validity of a self-reported measure of medication adherence. Med Care 1986;24:67-74.

18. Boas LCG-V, Lima MLSAPde, Pace AE. Adherence to treatment for diabetes mellitus: validation of instruments for oral antidiabetics and insulin. Rev Lat Am Enfermagem 2014;22:11-18.

19. Ahmad NS, Ramli A, Islahudin F, et al. Medication adherence in patients with type 2 diabetes Mellitus treated at primary health clinics in Malaysia. Patient Prefer Adherence 2013;7:525-30.

20. Fadheel JQ, Mohammed AJ. Adherence to therapy among Iraqi patients with type 2 DiabetesMellitus. $J$ Health Med Nurs 2016;32:75-82.

21. Lafta RK, Salih AA, Sadiq MA. Knowledge and attitude towards insulin therapy among type 2 diabetics. Iraqi J Comm Med 2011;24:196-9.

22. Mikhael EM, Hassali MA, Hussain SA, et al. Self-management knowledge and practice of type 2 diabetes mellitus patients in Baghdad, Iraq: a qualitative study. Diabetes Metab Syndr Obes 2019;12:1-17.

23. Australian Diabetes Educators Association. Clinical guiding principles for sick day management of adults with type 1 and type 2 diabetes. Technical document. Canberra: Australian Diabetes Educators Association, 2016
24. Morisky DE, Ang A, Krousel-Wood M, et al. Predictive validity of a medication adherence measure in an outpatient setting. $J$ Clin Hypertens 2008;10:348-54.

25. Lavsa SM, Holzworth A, Ansani NT. Selection of a validated scale for measuring medication adherence. J Am Pharm Assoc 2011;51:90-4.

26. Zongo A, Guénette L, Moisan J, et al. Predictive validity of selfreported measures of adherence to Noninsulin Antidiabetes medication against control of glycated hemoglobin levels. Can J Diabetes 2016;40:58-65.

27. Lippi G, Targher G. Glycated hemoglobin ( $\mathrm{HbA} 1 \mathrm{c})$ : old dogmas, a new perspective?. Clin Chem Lab Med 2010;48:609-14.

28. association Adiabetes. Introduction: Standards of Medical Care in Diabetes-2018. Diabetes Care 2018;41(Suppl 1):S1-S2.

29. Rattray J, Jones MC. Essential elements of questionnaire design and development. J Clin Nurs 2007:16:234-43.

30. Tinsley HE, Tinsley DJ. Uses of factor analysis in counseling psychology research. J Couns Psychol 1987;34:414-24.

31. Whooley MA, Avins AL, Miranda J, et al. Case-finding instruments for depression. Two questions are as good as many. J Gen Intern Med 1997;12:439-45.

32. Lalkhen AG, McCluskey A. Clinical tests: sensitivity and specificity. Continuing Education in Anaesthesia Critical Care \& Pain 2008;8:221-3.

33. Streiner DL, Norman GR. Health measurement scales: A practical guide to their development and use. 4th ed. New York: Oxford University Press Inc, 2008.

34. Pedersini R, Vietri J. Comparison of the 4-item and 8-item Morisky Medication Adherence Scale in patients with type 2 diabetes. Value in Health 2014;17.

35. Bhatnagar R, Kim J, E. Many J. Candidate surveys on program evaluation: examining instrument reliability, validity and program effectiveness. Am J Educ Res 2014;2:683-90.

36. Krapek K, King K, Warren SS, et al. Medication adherence and associated hemoglobin $\mathrm{A}_{1 c}$ in type 2 diabetes. Ann Pharmacother 2004;38:1357-62.

37. Schectman JM, Nadkarni MM, Voss JD. The association between diabetes metabolic control and drug adherence in an indigent population. Diabetes Care 2002;25:1015-21.

38. Lingam R, Scott J. Treatment non-adherence in affective disorders. Acta Psychiatr Scand 2002;105:164-72.

39. Lee W-Y, Ahn J, Kim J-H, et al. Reliability and validity of a selfreported measure of medication adherence in patients with type 2 diabetes mellitus in Korea. J Int Med Res 2013;41:1098-110.

40. Del Brutto $\mathrm{OH}$, Mera RM, Atahualpa Project Investigators. The importance of people compliance (social desirability bias) in the assessment of epilepsy prevalence in rural areas of developing countries. Results of the Atahualpa project. Epilepsia 2016;57:e221-4.

41. Bulmer M, Warwick DP. Social research in developing countries: surveys and Censuses in the Third World. London: Taylor and Francis, 2000.Page 211. First edition 1993, reprinted.

42. Tan X, Patel I, Chang J. Review of the four item Morisky Medication Adherence Scale (MMAS-4) and eight item Morisky Medication Adherence Scale (MMAS-8). lip 2014;5.

43. Moons KG, van Es GA, Deckers JW, et al. Limitations of sensitivity, specificity, likelihood ratio, and Bayes' theorem in assessing diagnostic probabilities: a clinical example. Epidemiology 1997;8:12-17.

44. Simel DL, Samsa GP, Matchar DB. Likelihood ratios with confidence: sample size estimation for diagnostic test studies. J Clin Epidemiol $1991 ; 44: 763-70$ 